\title{
Effect of Microwave and Conventional Autoclave Post- Curing on the Mechanical and Micro-structural Properties of Particulate Reinforced Polymer Matrix Composites
}

\author{
Adeodu Adefemi ${ }^{1,}$, , Anyaeche Christopher ${ }^{1}$, Oluwole Oluleke ${ }^{2}$, Alo Oluwaseun ${ }^{3}$ \\ ${ }^{1}$ Department of Industrial and Production, University of Ibadan, Ibadan, Nigeria \\ ${ }^{2}$ Department of Mechanical Engineering, University of Ibadan, Ibadan, Nigeria \\ ${ }^{3}$ Department of Mechanical and Mechatronics Engineering, Afe Babalola University, Ado Ekiti, Nigeria \\ Email address: \\ Femi2001ng@yahoo.com (A. O. Adeodu), osita.anyaeche@mail.ui.edu.ng (C. O. Anyaech), oluwoleo2@asme.org (O. O. Oluwole), \\ seunalloy@yahoo.com (O. A. Alo)
}

\section{To cite this article:}

Adeodu Adefemi, Anyaeche Christopher, Oluwole Oluleke, Alo Oluwaseun. Effect of Microwave and Conventional Autoclave Post-Curing on the Mechanical and Microstructural Properties of Particulate Reinforced Polymer Matrix Composites. Advances in Materials.

Vol. 4, No. 5, 2015, pp. 85-94. doi: 10.11648/j.am.20150405.11

\begin{abstract}
The application of polymer matrix composites has found valuable in many engineering fields like electrical, marine, aerospace, electronics and microelectronics. Thus, a new technique like microwave through electromagnetic energy was explored for processing of polymer matrix composite. The roles of microwave in the post curing of polymer matrix composites cannot be underestimated, as it has the capacity to improve the mechanical and micro-structural properties of the composite produced. The aim of the study is to investigate the effect of microwave post curing on the mechanical and microstructural properties of particulate reinforced polymer matrix composites. These effects were compared with composites post cured using conventional autoclave oven with the objective of investigating the significance of microwave curing on the tensile strength and structural qualities in terms of defects of the produced composites. A specific study comprising of aluminum filled polyester based composite and carbon black filled polyester based composite were investigated using two different composite curing methods (microwave oven and conventional autoclave oven). The investigation, through experimentation was based on mechanical property (tensile strength) and micro-structural quality (defects) of the produced composites. Comparing the results of the post-curing of the composites using microwave and conventional methods, there is direct relationship between the tensile strength and the percentage weight fraction of the fillers with respect to the post curing methods. $30 \%$ aluminium filled, post cured in microwave has $0.01 \mathrm{MPa}$ tensile strength, 20\% aluminium filled (microwave) has $0.0076 \mathrm{MPa}$ while $30 \%$ aluminium filled (conventional oven curing) has $0.0092 \mathrm{MPa}$ and $20 \%$ aluminium filled (conventional oven curing) has $0.0068 \mathrm{MPa}$. Also, composites post-cured with microwave show less voids defect compared to that post-cured by conventional autoclave oven. It was shown in this paper that post-curing of the particulate composites through microwave was able to improve the tensile strength and minimize defects better as compared to conventional autoclave method.
\end{abstract}

Keywords: Autoclave, Curing, Micro-Structure, Microwave, Polymer Matrix Composites, Tensile Strength

\section{Introduction}

Electromagnetic energy has been employed for many years for industrial applications, including wood drying and bread processing [1]. There are several ways in which electromagnetic energy can be applied, such as induction, radio-frequency $(\mathrm{RF})$ or microwave [1]. The main difference is the frequency at which these techniques operate. Depending on the material to be processed, the different frequencies can offer different levels of performance [1].
Although RF and microwave operate in a similar way, microwaves can offer better uniformity. However, both RF and microwave are usually limited to dielectric materials with specific dipolar properties [1].

Particulate composites are commonly used today in many aerospace and industrial applications [2]. They offer a wide range of attractive material properties, both mechanical and physical, that cannot be achieved using conventional engineering alloys [2]. These enhanced materials properties are the direct result of the interaction between the matrix and 
the reinforcement [3].

In a particulate composite materials system, the reinforcement strengthens the matrix both extrinsically, by load transfer to the particulate reinforcement, and intrinsically, by increasing dislocation density [3-4]. The interaction between the particulate reinforcement and the matrix is the basis for the enhanced structural and materials properties associated with particulate composite materials systems. Composite materials properties can be tailored to meet specific engineering requirements by selecting a particular reinforcement and varying the amount added to the matrix. In this fashion, the structural and mechanical properties of the composite materials system can be controlled with some independence [5].

Increasing the reinforcement volume in a composite system increases mechanical properties, such as elastic modulus, ultimate strength, and yield strength, while reducing the thermal expansion and, in some cases, the density of the composite system. Unfortunately materials properties such as ductility and fracture toughness typically decrease with increasing reinforcement volume [2] [6].

The increase in the elastic modulus, strength (ultimate and yield) and improved structural quality is believed to be due to the difference in thermal expansion between the reinforcement particles and the matrix during curing. Most reactions in polymer matrix composites are condensation type, thus there is possibility of gases been trapped in between the composite during curing depending on the method used. The trapped bubbles constitute voids in the composite when finally cure which may render the products useless if too much [7]. Also during the production of these composites, both the reinforcement and matrix are heated to processing temperature, brought to curing condition of matrix, and then allowed to cool. The thermal contraction of the matrix during cooling is typically much greater than that of the reinforcement, which leads to a geometric mismatch [2]. At the particle-matrix interface, this geometrical disparity creates mismatch strains that are relieved by the generation of dislocations in the matrix originating from sharp features on the ceramic reinforcement. Discontinuously reinforced matrix composite materials systems are commonly used in applications that require high specific materials properties, enhanced fatigue resistance, wear resistance, controlled expansion. Additionally, composite may be designed to yield a materials system that offers multiple roles [8]. Some examples of multiple roles that particulate composite materials systems offer include high strength and fatigue resistance for aerospace and mechanical applications, moderate strength and neutron absorption capabilities for nuclear applications, high strength and wear resistance for heavy equipment applications, and impact/energy dissipation for armor applications [8]. The correct selection of reinforcement is very important in yielding desired resultant materials properties. An improper reinforcement selection may lead to less-than-desirable composite materials properties, difficulty in fabrication of end product, poor quality and high cost [9]. The aim of the study is to investigate microwave post-curing of polymer matrix composites. The effects were compared with that post-cured using conventional autoclave oven with the objectives to determine the effectiveness of microwave post curing to improve the tensile strength and structural quality in terms of defects of the produced composites.

\section{An Overview of Prospects of Microwave Processing}

The application of microwave energy to the processing of various materials such as ceramics, metals and composites offers several advantages over conventional heating methods [10]. These advantages include unique microstructure and properties, improved product yield, energy savings, reduction in manufacturing cost and synthesis of new materials [11].

Nightingale [12] compared autoclave cured composites to microwave post-cured, autoclaved composites and fully microwave cured composites. The flexure test results showed that microwave post-cured composites produced the lowest mechanical performance, with the conventional autoclave cured composites producing the highest. Lee and Springer [13] even reported microwave curing of multidirectional composites as unsuccessful where no cure was achieved. Other studies have shown that microwave heating produced an improvement in the mechanical and interfacial properties. This is believed to be due to better adhesion between the fibre-matrix interface (in the case of carbon-epoxy composites) as carbon fibres absorb most of the microwaves and therefore 'locally' heat the interface first, as opposed to relying on conduction/convection as reported by Wei et al. [14] and also possibly due to a reduction in thermal residual stress as microwaves heat through the material. Certain studies, such as those carried out by Boey and Yue [15-16], reported an increase in elastic modulus but a decrease in tensile strength for microwave cured composites compared with thermally cured ones. The inconsistency in the results obtained by past research makes it difficult to draw a clear conclusion. It is believed that this can be attributed to three reasons. First is due to the different equipment employed by the researchers. This is critical as in many cases, microwave field homogeneity is not achieved and therefore the measured performance depends on the location of the sample within the chamber. Secondly by the different experimental techniques employed, e.g. some used time and power as reference, whereas others used temperature; some employed pressure, others did not, etc. And finally, due to the different materials used. The curing mechanism and its interaction with microwaves differ between materials of different chemical structures.

In term of compressive strength, Akay et al [17] investigated the moisture absorption behaviour of kevlar49/epoxy-resin laminates when the samples were cured using autoclave and microwave oven. They concluded that moisture absorption of the specimens deteriorates approximately $5 \%$ per $1 \%$ absorbed moisture. Jian Zhou et al 
[18], through research proved that curing of epoxy resins with maleic anhydride as the curing agent using microwave curing technique increased the compressive strength when compared with the thermal curing technique. They also proved that the amount of maleic anhydride used as curing agent can be this time reduced by about 5\%. Thus, concluding that microwave processing of polymer is an efficient and energy-saving technology.

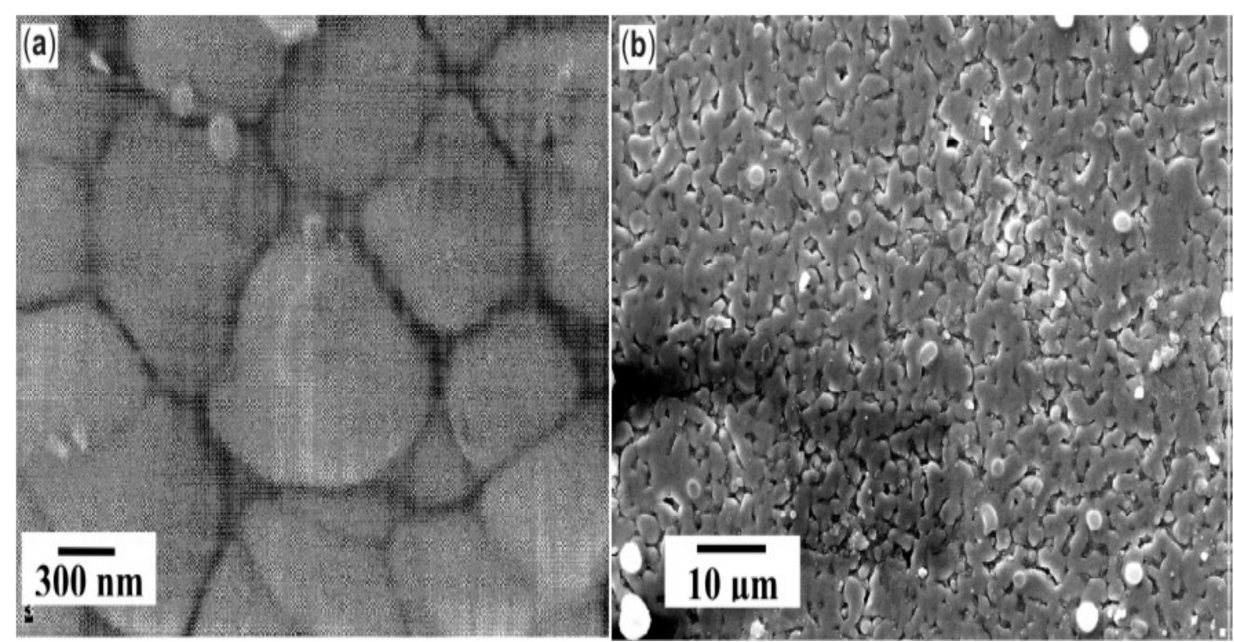

Source: [10]

Figure 2.1. Microstructures of sintered titanium samples: (a) microwave and (b) conventional.
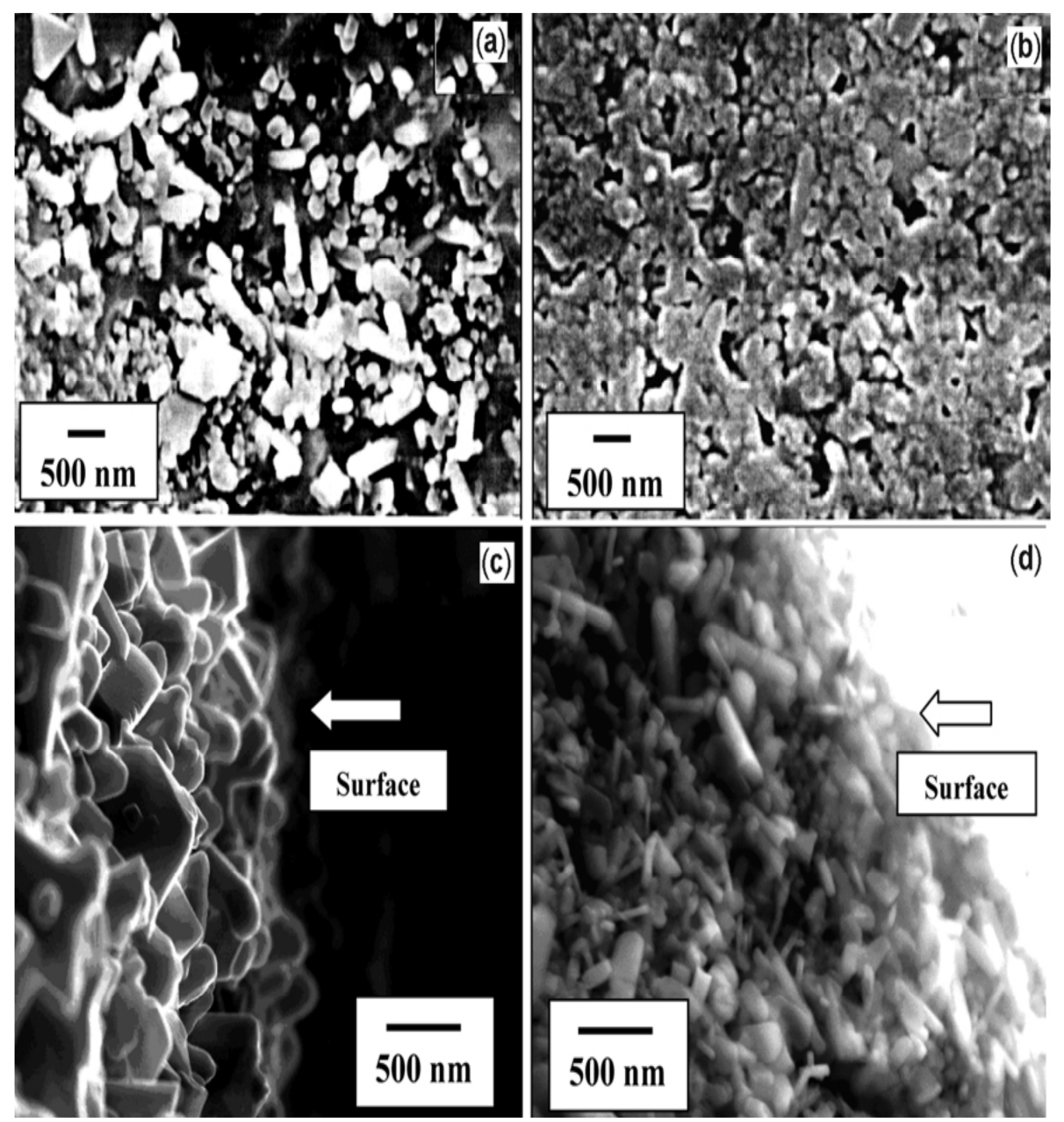

Source: [22]

Figure 2.2. Surface microstructures of the glass-ceramic coatings obtained by heat treatments of the glass coatings for 90 min at $880^{\circ} \mathrm{C}$ followed by 90 min at $1020^{\circ} \mathrm{C}$ : (a) conventional, (b) microwave and cross-sectional microstructures showing surface regions of the similar coatings, (c) conventional (d) microwave. 
Bambang Soesatyo et al [19], investigated polycarbonate sandwich joined with a fast cured epoxy adhesive and found that microwave cured adhesives had higher tensile bond strength when processed with addition of Sterling carbon black dopant polycarbonate butt joint specimens. They also concluded that high bond strength in microwave cured resulted in a uniform stress level across the joint surface. Bai et al [20], compared the mechanical behavior of epoxy resin cured by microwaves and one cured thermally and concluded that, microwave cured resin have a little higher tensile strength and Young's modulus than thermally cured resins because of greater homogeneity. Further, the tensile strength and Young's modulus of microwave cured resins increased with the strain rate. Bai et al [20], investigated unidirectional continuous E-glass fibre/epoxy composites cured using both thermal and microwave. Mechanical behaviour of the composites was studied by in situ transverse tensile tests and they concluded that fiber-matrix interface of microwave cured is stronger than that of thermally cured composites. Also more voids exist in microwave cured composites then thermal cured composites when rupture mechanism was analyzed. This difference was noted due to the shorter time and lower applied pressure of microwave curing composites. Chaowasakoo et al [21], studied fly ash/epoxy composites cured by both thermal and microwave curing methods using differential scanning calorimeter and determine that the composites cured by microwave consumed shorter cure time and had higher ultimate strengths especially impact strength, and strain at break than those by the conventional thermal cure. They concluded that the tensile strength of the microwave cured composites increased with increasing fly ash content in microwave cured composites, whereas tensile strength decreased in thermally cured composites.

In terms of microstructures, Kwak et al [1] studied gerits $600 \mathrm{~g}$ unidirectional low modulus carbon fibre reinforced epoxy WE91-2 composite, typically employed for the production of wind turbine blades using vacuum bagging and post-cure using conventional and microwave. It was observed that similar void contents were resulted between the conventionally cured and microwave cured composites. Das et al [22] worked on sintering of titanium powder and discovered that sintered titanium had finer microstructure (average grain size $1.29 \mu \mathrm{m}$ ) in comparison to that of conventionally sintered titanium (average grain size $3.6 \mu \mathrm{m}$ ).

Crystallization of $\mathrm{MgO}-\mathrm{Al}_{2} \mathrm{O}_{3}-\mathrm{TiO}_{2}$-based glass coating with identical composition was conducted by Das et al using microwave and conventional heat treatment processes. Finer crystallites were generated in the glass coating by microwave processing than the sizes of the crystallites obtained in the conventionally processed coating [23].

\section{Methodology}

\subsection{Material and Equipment Selection}

The materials (unsaturated polyester resin, aluminum powder and carbon black reinforcement) and equipment used in this study are the same as used by Adeodu et al [24]

\subsection{Composite Manufacturing Process}

The composite manufacturing process is the same as used by Adeodu et al [24]. Alongside with the post curing, is the characterization of the composite samples, where mechanical and microstructure properties of the composite samples were determined. The mechanical and micro-structural properties of the composites were determined by universal testing machine for tensile strength and optical scan microscope for detection of defects in the samples respectively.

\subsection{Properties Characterization and Testing}

\subsubsection{Determination of Mechanical Properties under Compression}

The tensile strength is the maximum strength that material can withstand without breaking. It is the highest point in stress - strain curve. It can be determine by:

Tensile Strength = Maximum Load/ Cross-Sectional Area 3.1

The tensile test was carried out using universal testing machine. The indenters were loaded on the measuring scale. The gauge length of the indenters was set to $3 \mathrm{~cm}$ on the measuring scale which was laid on the compression testing machine diagonally for maximum stability. As shown in figure 3.1, vernier calliper was used to measure the width and thickness of the specimens. The sample loads were placed at a distance between the two indenters on the compression testing machine. Electronic micrometer was connected to the testing machine so that elongation of specimens with increase in the tensile load can be traced. Care must be taken so that samples do not slip from its grip by using the right size of jaw. Select appropriate pressure on the samples that will neither cause breaking of the sample nor slip. 


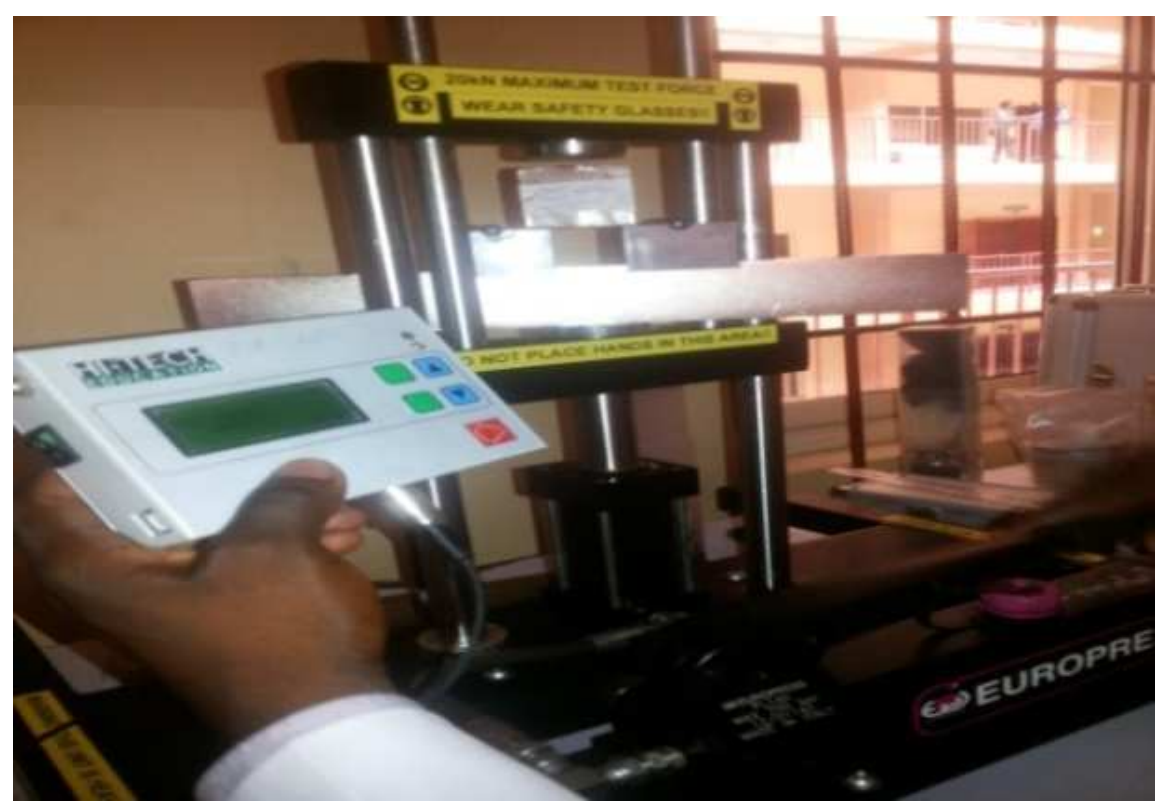

Figure 3.1. Tensile Property measurement in Progress.

\subsubsection{Optical Morphological Observations}

Defects in the fabricated composites are mainly in the form of voids, delaminations and lack of wetting during resin mixing. In this study optical scan was used to study the defects in the composite panels. Optical scan was used to gauge the extent of defects in each cured laminate prior to testing. Optical scan did not give an absolute value of void content but it could detect which panel contained more defects than others.

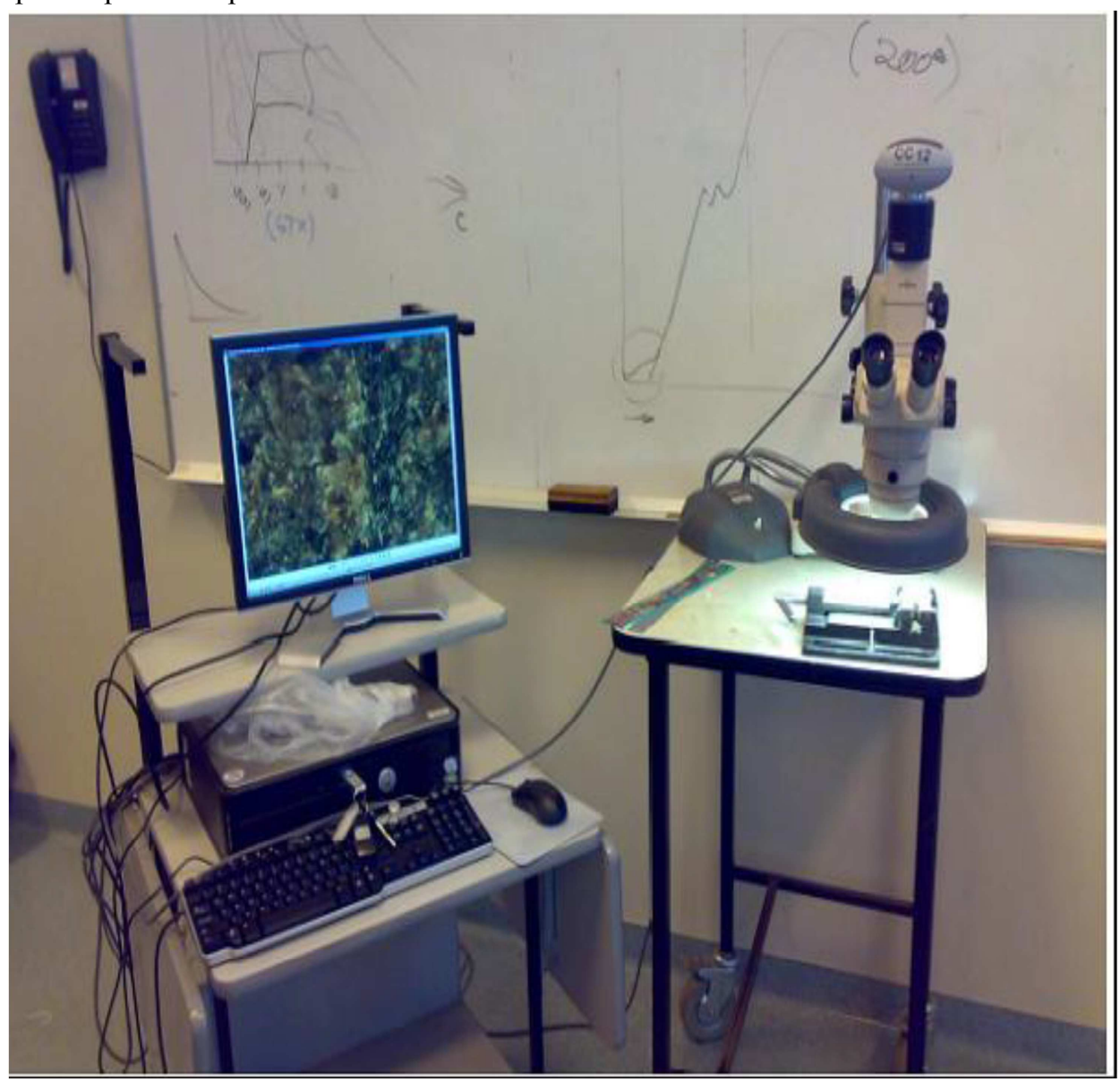

Figure 3.2. Microstructure Analysis in Progress. 


\section{Results Discussion}

4.1. Comparison of Tensile Strength between the Microwave and Conventional Heating for Polyester-Aluminum Composite and Polyester - Carbon Black Composites

Table 4.1. Maximum Force and Tensile Strength of Composites Sujected to Microwave Curing.

\begin{tabular}{llll}
\hline Percentage Weight Fraction of Samples (wt\%) & Cross - Sectional Area of Samples $\left(\mathbf{m m}^{2}\right)$ & Maximum Force (kN) & Tensile Strength (MPa) \\
\hline $30 \%$ Aluminium filled Polyester Composite & 2500 & 25 & 0.01 \\
$20 \%$ Aluminium filled Polyester Composite & 2500 & 19 & 0.0076 \\
$10 \%$ Aluminium filled Polyester Composite & 2500 & 13 & 0.0052 \\
$20 \%$ Carbon Black filled Polyester Composite & 2500 & 10 & 0.0040 \\
$10 \%$ Carbon Black filled Polyester Composite & 2500 & 8 & 0.0032 \\
\hline
\end{tabular}

Table 4.2. Maximum Force and Tensile Strength of Composites Subjected to Conventional Oven Curing.

\begin{tabular}{llll}
\hline Percentage Weight Fraction of Samples (wt $\%)$ & Cross - Sectional Area of Samples $\left(\mathbf{m m}^{2}\right)$ & Maximum Force (kN) & Tensile Strength (MPa) \\
\hline $30 \%$ Aluminium filled Polyester Composite & 2500 & 23 & 0.0092 \\
$20 \%$ Aluminium filled Polyester Composite & 2500 & 17 & 0.0068 \\
$10 \%$ Aluminium filled Polyester Composite & 2500 & 12 & 0.0048 \\
$20 \%$ Carbon Black filled Polyester Composite & 2500 & 7 & 0.0028 \\
$10 \%$ Carbon Black filled Polyester Composite & 2500 & 5 & 0.0020 \\
\hline
\end{tabular}

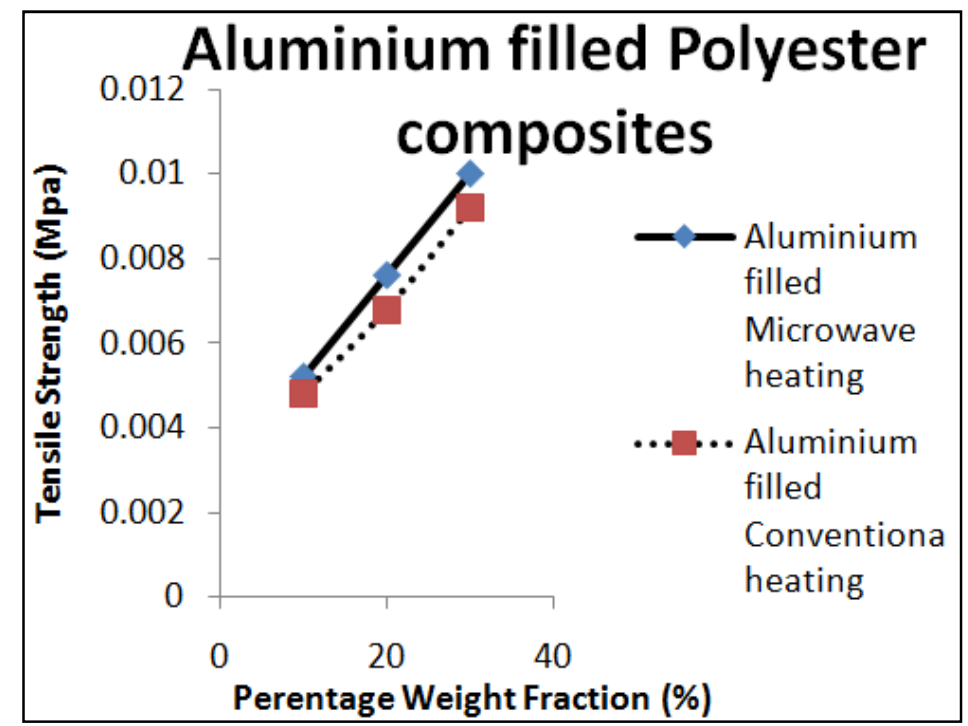

Figure 4.1a. Tensile Strength Curves for varying weight fractions of Aluminium filled Polyester Composite for Microwave and Conventional Oven Curing.

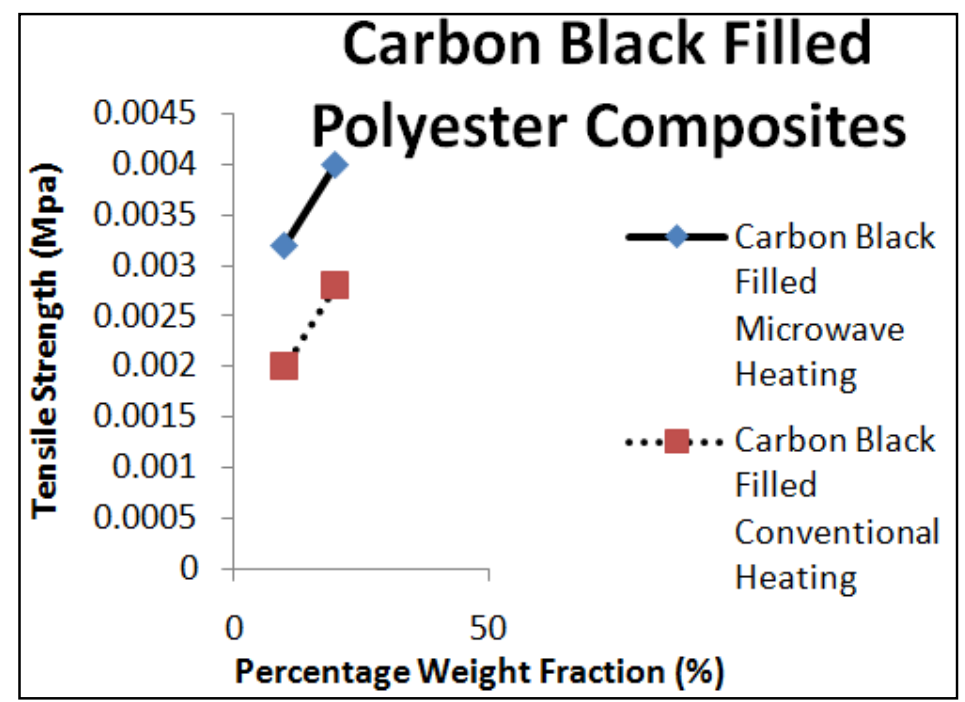

Figure 4.1b. Tensile Strength Curves for varying weight fractions of Carbon Black filled Polyester Composite for Microwave and Conventional Oven Curing. 
Figures $4.1 \mathrm{a} \& \mathrm{~b}$ show the relationship between the tensile strength and percentage weight fraction of fillers (aluminium and carbon black) used for both microwave and conventional oven heating respectively. There was a general agreement in the two curves that percentage weight fraction of the particulate reinforcement has high impact on the tensile strength of the two composite systems. There is direct relationship between the tensile strength and the percentage weight fraction of the fillers with respect to the post curing methods. $30 \%$ aluminium filled, post cured in microwave has $0.01 \mathrm{MPa}$ tensile strength, $20 \%$ aluminium filled (microwave) has $0.0076 \mathrm{MPa}$ while $30 \%$ aluminium filled (conventional oven curing) has $0.0092 \mathrm{MPa}$ and $20 \%$ aluminium filled (conventional oven curing) has $0.0068 \mathrm{MPa}$. This result can be traced to the statement from the literature [25-30] that the degree of reinforcement or improved mechanical properties in a composite is dependent on the level of bonding at the matrix - particle interface. Therefore, higher percentage weight fraction of the particulates reinforcement increases the bonding of the constituent at the interface. Similar impact was experienced for carbon black filled polyester composites.

Comparing figures $4.1 \mathrm{a} \& \mathrm{~b}$, it was observed that aluminium filled polyester composite samples have higher tensile strength compared to carbon black filled polyester composite samples both in microwave curing and conventional oven curing. For example, 20\% aluminum filled polyester (microwave curing) has strength of $0.0076 \mathrm{MPa}, 20 \%$ aluminium filled polyester (conventional curing) has $0.0068 \mathrm{MPa}$, whereas $20 \%$ carbon black filled polyester has strength of $0.004 \mathrm{MPa}$ and $20 \%$ carbon black filled polyester (conventional curing) has $0.0028 \mathrm{MPa}$ respectively. This may be traced to metallic fillers more reactive than non metallic which resulted in higher degree of cross-linking in the aluminum filled polyester composite than that of carbon black filled polyester composite.

More observations were made by further comparing the tensile strength of composites curred by microwave oven to those curred by conventional oven. It was observed that the two systems of composite have higher tensile strength when curred in microwave oven to those curred using conventional oven. These show the effectiveness of microwave oven curring of composites in improving mechanical properties of composites than conventional oven.

\subsection{Comparison of Microstructure Properties between the Microwave and Conventional Heating for Polyester- Aluminum Composite and Polyester-Carbon Black Composites}

Figure 4.2 and 4.3 show the micro structural scans of the post-cured samples using microwave and conventional autoclave oven. These figures show effect of the post-curing techniques on the microstructure properties in terms of voids and delaminations in aluminum filled polyester and carbon black filled polyester composites. Voids are caused by trapped hydroscopic water and water vapour bubble within the parts during lamination [31]-[33]

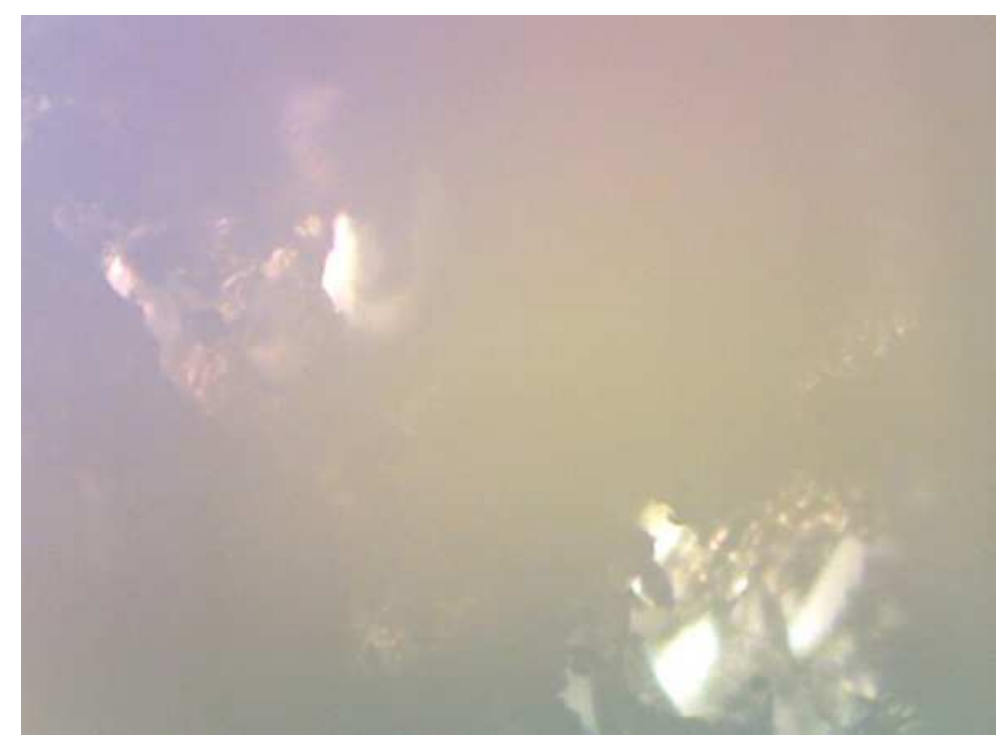

Figure 4.2a. Micrograph of CB filled Polyester Composite Cured with Conventional Oven.(Mag x100um) 
Adeodu Adefemi et al: : Effect of Microwave and Conventional Autoclave Post-Curing on the Mechanical and Microstructural Properties of Particulate Reinforced Polymer Matrix Composites

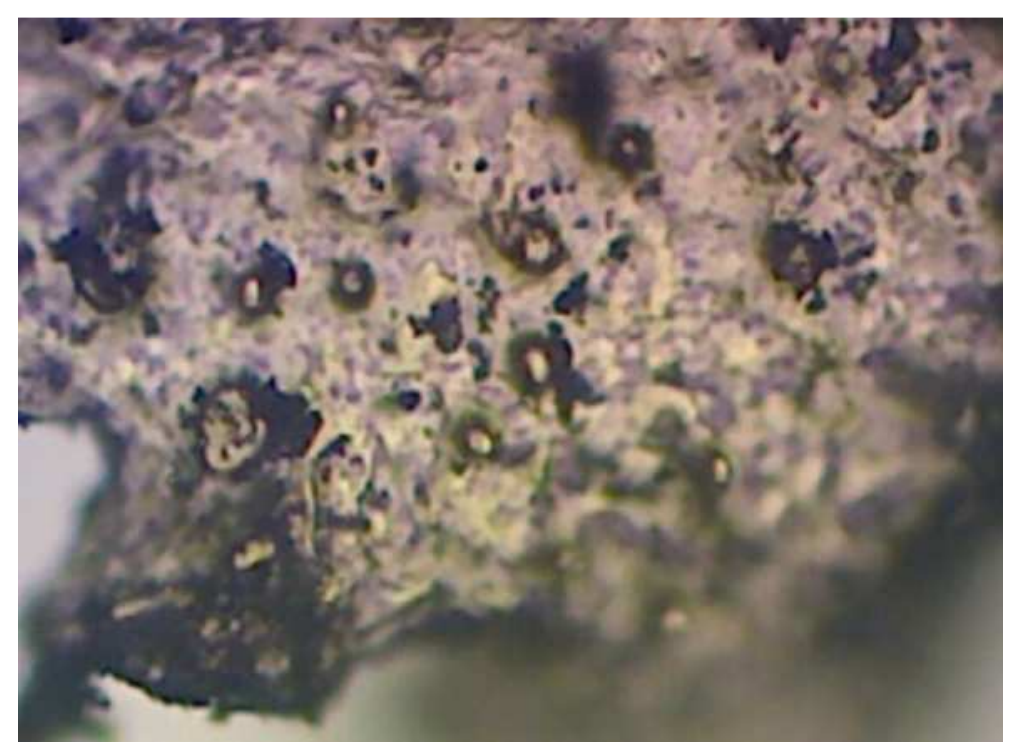

Figure 4.2b. Micrograph of Aluminum filled Polyester Composite Cured with Conventional Oven. (Mag x100um).

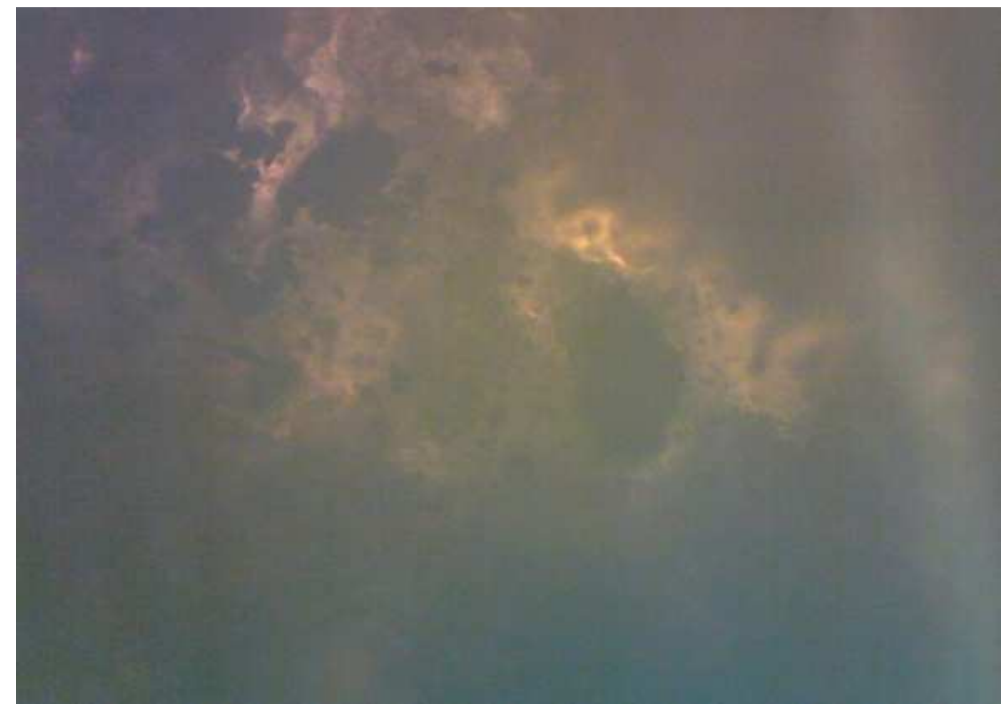

Figure 4.3a. Micrograph of CB filled Polyester Composite Cured with Microwave Oven. (Mag x100um).

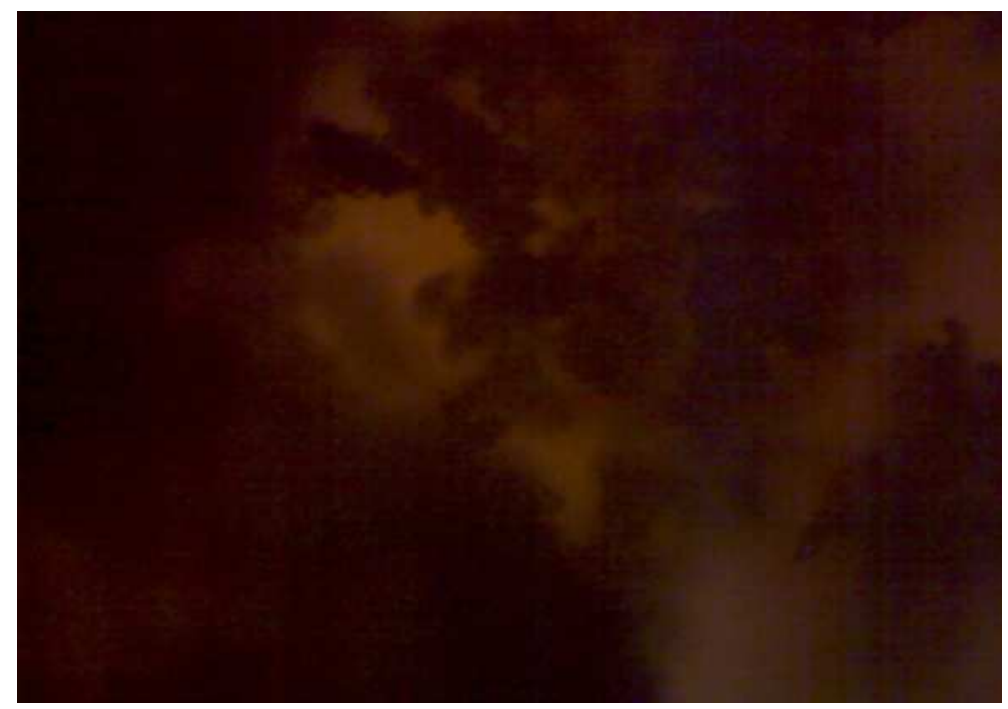

Figure 4.3b. Micrograph of Aluminum filled Polyester Composite Cured by with Microwave Oven. (Mag x100um). 
In figure $4.2 \mathrm{a} \& \mathrm{~b}$, it was observed that part surface of the samples cured with conventional autoclave oven were full of voids more than those cured with microwave oven. This could be traced to the statement made by Philips [34], that some polymers undergo condensation type chemical reactions during curing which produce volatile reactants. The higher exterior temperature of conventional heating technique tends to advance curing at the surface of the parts, sometimes forming a hard impermeable skin on the part surface which can trap the volatiles given off during the condensation type reaction. Trapped volatiles usually result in excessive voids and delaminations, essentially rendering the finished part useless.

\section{Conclusions}

1. The use of microwave oven curring of composites improves mechanical properties of composites better than conventional oven.

2. The use of microwave oven curring of composites facilitates microstructural properties of the composites better than conventional autoclave oven

\section{References}

[1] Kwack M., Robinson P., Bismarck A., Wise R., (2011). Curing of composite materials using the recently developed Haphaistos microwave. $18^{\text {th }}$ International Conference on composites materials, Korea, Aug. 21-26

[2] Hussein Mohammed (2012). The effect of curing time on the mechanical properties of polyester reinforced aluminum particulate composite. Nahrain University college of Engineering Journal. Vol. 15, No 2, pp 197-225

[3] Hertzberg R.W., (1989). Deformation and fracture mechanics of engineering materials", 3rd ed., John Wiley \& Sons

[4] Sunain Katoch, Vinay Sharma, P. P. Kundu, (2010). Swelling Kinetics of unsaturated polyester layered silicate nanocomposite depending on the fabrication Mmethod", The Open-Access Journal for the Basic Principles of Diffusion Theory, Experiment and Application, 13(1), pp 1-31

[5] Grayson M and Eckroth, D Ed., (1982). Encyclopedia of chemical technology", 3rd ed., Vol 18, John Wiley \& Sons, p 575

[6] Philip C. Sturman and Rexford N. Y. (1999). Induction Heating of Polymer Matrix Composite Fibre Strands. SAMPE Journal, Vol. 26, No 4

[7] Das S, Mukhopadhyay A K, Datta S and Basu D (2009) Bull. Mater. Sci., Vol. 32, No. 1

[8] Daniel B. Miracle and Steven L. Donaldson were the Volume Chairs, (2001). Asm Hand Book, Volume 21, Composite, ASM International Handbook Committee,

[9] Dominick V Rsato and Donal V Rosat, (2003). Plastics Engineering Products Design", Elsevier Ltd, The Boulevard, Langford Lane, Kidlington, Oxford OX5 1GB, UK, p 5
[10] Sutton, W.H. (1989). Microwave Processing of Ceramics, Ceramic Bulletin, 68(2), 376-86

[11] Das S, Mukhopadhyay A K, Datta S and Basu D (2008b) (communicated)

[12] Nightingale, C (2000). Microwave assisted curing of epoxy resins and composites", PhD Thesis. University of Manchester, UK

[13] Lee, W and Springer, G (1984). Microwave curing of composite. Journal of Composite Materials, Vol.18, No.4, pp 387-409

[14] Wei, J., Chang, Y., Thomas, B and Hawley, M (1991). Microwave Heating of Thick-Section Graphite Fiber/Epoxy Composite. Proceedings of ICCM-8, Vol.1, pp10-L-1 to 10-L10

[15] Boey, F and Lee, T (1991). Electromagnetic Radiation Curing of an Epoxy/Fibre Glass Reinforced Composit, Radiation Physics and Chemistry, Vol.38, No.4, pp 419-42

[16] Yue, C and Boey, F (1993). The Effect of Microwave and Thermal Curing on the Interfacial Properties of an Epoxy/Glass Composite. 2nd International Conference on the Deformation and Fracture of Composites, pp. 121-128

[17] Akay, M and Kong Ah Mun, (1995). Bearing strength of autoclave and oven cured Kevlar/epoxy laminates under static and dynamic loading, Composites, 26, pp.451-456, (Receive August 1994; revised 7 October 1994)

[18] Jian Zhou, Chun Shi, Bingchu Mei, Runzhang Yuan, Zhengyi $\mathrm{Fu}$, (2003). Research on the technology and the mechanical properties of the microwave processing of polymer, Journal of Materials Processing Technology, 137, pp 156-158

[19] Bambang Soesatyo, Aaron Blicblau, Elias Siores, (1999). Effect of rapid curing doped epoxy adhesive between two polycarbonate substrates on the bond tensile strength", Journal of Materials Processing Technology, 89(90), pp.451-456

[20] Bai, S. L., Djafari, V., Andreani, M and Francois, D (1995). A comparative study of the mechanical behaviour of an epoxy resin cured by Microwaves with one cured thermally", European. Polymer Journal, 31, (9), pp.875-884. (Received 17 January 1994; accepted in final form 27 June 1994)

[21] Chaowasakoo, T., Sombatsompop, S., (2007). Mechanical and morphological properties of fly ash/epoxy composites using conventional thermal and microwave curing method. Composites Science and Technology, 67, pp.2282-2291

[22] Islam R. A and Chan Y. C. (2003). Effect of Microwave Preheating on the Bonding Performance of Flip chip on Flex Joint. Micro electronics Reliability. Vol. 44, pp 815-821

[23] Bai, S. L., and Djafari, V (1995). Interfacial properties of microwave cured Composites, Composites, 26, pp.645-651

[24] Adefemi O. Adeodu, Christopher O. Anyaeche, Oluleke O. Oluwole, Charles U. Omohimoria (2015). Effect of Microwave and Conventional Heating on the Cure Cycles of Particulate Reinforced Polymer Matrix Composites. International Journal of Materials Science and Applications. Vol. 4, No. 4, pp. 229-240

[25] Hossain M. R., Hossain M. F., Islam M. A., (2014). Effect of wood properties on the behaviors of wood particle reinforced polymer matrix composites. J. Sci. Res 6(3) Page 431-443 
[26] Azuke F., Aigbodion V. S., Abdulwahab M., Fayomi O. S.I., Popoola A. P.I., Nwoyi C. I., Garba B, (2012). Effect of bone particle on the properties and microstructure of polypropylene-bone ash particulate composites. Results in Physics 2 Page 135-141

[27] Chawla Nikhilesh and Yu Linshen (2001). Mechanical behavior of particle reinforced metal matrix composites. Advanced Engineering Material Vol. 6, page 1438-1656

[28] Shao-Yunfu, Xi-Qiao Feng, Bernd Lauke, Yiu-wing Mail (2008). Effect of particle size particle-matrix interface adhesion and particle loading on mechanical properties of particulate-polymer composites. Science Direct. Composites: part B, 39 Page 933-961

[29] Hassan S. B., Oghenevweta E. J., Aigbodion V. S (2012). Potential of maize stalk ash as reinforcement in polyester composites. Journal of Minerals Materials Characterization and Engineering. Vol. 11, No 4, Page 445-459

[30] Upadhyaya D D, Ghosh A, Gurumurthy K R and Prasad R (2001) Ceram. Int. 27415

[31] Nikki Sgriccia and Hawley M. C. (2007). Thermal Morphological and Electrical Characterization of Microwave Processed Natural Fibre Composites. Composites Science and Technology. Vol. 67, pp 1986-1991

[32] Yizhuo Gu, Min Li, Zuoguang Zhang and Zhijie Sun, (2012). Measuring Methods and Process Analysis of Void Formation Conditions for Resin Matrix Composites. Laboratory of Aerospace Materials and Performance. Beijing 100191, China

[33] Das S, Mukhopadhyay A K, Datta S and Basu D (2005) Trans. Ind. Ceram. Soc. 64143 